\title{
Comparison of the Effect of Radiofrequency and Laser Treatment on Mixed Urinary Incontinence and Vulvovaginal Atrophy in Iranian Menopausal Women: A Randomized Controlled Trial
}

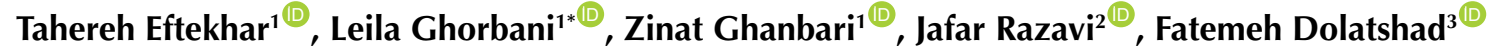

\begin{abstract}
Objectives: Radiofrequency (RF) and laser are minimally invasive methods that are used to treat mixed urinary incontinence (MUI) and vulvovaginal atrophy (VVA). The purpose of this study was to compare the effect of RF and laser on UI and VVA in Iranian menopausal women.

Materials and Methods: Two hundred and forty women participated in this randomized clinical trial, including those who referred to Valiasr hospital, Tehran, Iran and underwent MUI and VVA treatments in 2018. Participants were randomly divided into the RF $(n=80)$, laser $(n=80)$, and placebo $(n=80)$ groups. Before and after the intervention, UI was assessed using the International Consultation on Incontinence. Finally, pelvic organ prolapse/urinary incontinence sexual questionnaire, vaginal health index (VHI), and visual analog score were used to determine sexual satisfaction.

Results: VVA symptoms decreased in RF and laser groups after the intervention although changes in the RF group were more compared to the laser group $(15.813$ vs. $10.075, P<0.001)$. Contrarily, $\mathrm{VHI}$ improved in RF and laser groups after the intervention although changes in the RF group were more remarkable in comparison with the laser group $(10.425$ vs. $2.231, P<0.001)$. Based on the results, MUI symptoms decreased after the intervention in RF and laser groups although changes in the laser group were not significant $(P$ $<0.149)$. Eventually, emotional behaviors in the RF group improved after the intervention $(P=0.04)$ although changes in the laser group were not significant.

Conclusions: In general, a greater reduction was observed in the RF group regarding MUI and VVA symptoms compared to the laser group. In addition, using the RF method for the treatment of the genitourinary syndrome of menopause (GSM)symptoms had significantly greater effects on the improvement of the quality of life and sexual satisfaction of menopausal women compared to laser therapy. Thus, RF seems to be an effective and acceptable non-surgical method for the treatment of UI and VVA.

Keywords: Pulsed radiofrequency treatment, Laser therapy, Mixed urinary incontinence, Vulvovaginal atrophy, Genitourinary syndrome of menopause
\end{abstract}

\section{Introduction}

The genitourinary syndrome of menopause (GSM) is a common condition among half of the perimenopausal and postmenopausal women. From 2014, the term GSM replaced terms such as vulvovaginal atrophy (VVA) and atrophic vaginitis (1).

GSM is significantly associated with some vaginal and urinary symptoms such as urinary incontinence (UI), urinary frequency, vaginal dryness, dyspareunia, and burning sensation that appear because of the VVA (2). These symptoms significantly affect the quality of life of large populations of women (3). Meanwhile, the estimations of the crude prevalence rate of UI range from 16.1 to $68.8 \%$ in cross-sectional studies (4). In addition, the prevalence of VVA is consistently reported at around $84 \%$ among menopausal women (1). Due to the embarrassment and a belief that their symptoms are a natural part of aging, only about $25 \%$ of affected women may be reluctant to seek help from a healthcare professional (5). Probably, the knowledge of treatment options and the effectiveness of these methods can persuade women to seek treatment for their symptoms (6). There are several non-surgical ways for treating VVA and UI. If estrogen therapy does not contain any contraindications for the patient, oral or topical estrogen is used to treat VVA (7). Further, a pelvic floor training program guided by a physiotherapist is recommended as first-line therapy for women with UI symptoms (8).

Today, minimally invasive methods are proposed to improve both VVA and UI symptoms. Laser treatment through a depth-controlled photo-thermal action, using pulsed $\mathrm{CO}_{2}$ or Er:YAG laser, leads to the induction of 


\section{Key Message}

- VHI in RF and laser groups improved after the intervention although changes in the RF group were more compared to the laser group.

- In addition, emotional behaviors in the RF group improved after the intervention.

- RF seems to be an effective and acceptable non-surgical method for the treatment of UI and VVA

collagen denaturation, the shrinkage of mucosa and the underlying supportive tissue without destruction, enriching, and tightening and more elasticity of tissues (9-11). Radiofrequency (RF) is another safe, non-surgical method with minimal risk of adverse effects which emits high-frequency wavelengths to the tissue impedance, resulting in a local temperature increase, inducing the synthesis of collagen by fibroblasts and denaturation collagen without significant necrosis or injury to nearby vascular or nerve tissues $(3,12,13)$. These two methods are used for collagen contraction, neocollagenesis, vascularization, and improvement of the elasticity, tension, and rejuvenation of the vulvo-vagina (14).

A few studies with small study populations and shortterm follow-ups have been carried out to assess the safety and efficacy of laser treatment and RF devices, as well as the clinical response of patients with GSM symptoms such as UI and VVA (11).

Considering the safety of noninvasive methods such as laser therapy and RF for the treatment of GSM symptoms in affected women, this study was conducted to compare the effect of RF and laser treatment on MUI and VVA in Iranian menopausal women referring to the pelvic floor clinic of Valiasr hospital, Tehran, Iran.

\section{Materials and Methods}

Study Design and Population

This randomized clinical trial included all Iranian menopausal women with UI symptoms referring to Valiasr hospital, Tehran, Iran in 2018. The inclusion criteria were history of UI symptoms, sexual intercourse, sexual problems due to VVA, at least one year after the termination of menstruation, the presence of VVA symptoms, and sexual dysfunction. On the other hand, the exclusion criteria included patients with urinary infection, hematuria, pelvic organ prolapse, Pelvic Organ Prolapse Quantification (POP-Q) $>2$, pregnancy, childbirth in less than a year, abnormal vaginal bleeding, damaged vaginal tissue, history of damage to spinal nerves, radical hysterectomy with neuropathy, epilepsy, autoimmune diseases, and $>50 \mathrm{~g}$ of urine leakage per hour. In general, 246 eligible patients were recruited in this study using the available sampling method. The sample size was estimated as 71 patients per group considering the power of $80 \%$ and a $95 \%$ confidence interval. Finally, 82 people were included given a $10 \%$ drop in each group. Participants were randomly allocated to three laser, RF, and control groups. The flow diagram of the trial according to CONSORT is visualized in Figure 1.

\section{Procedure}

After obtaining the approval of the Ethics Committee of Tehran University of Medical Sciences, general information about the study and its goals was provided to eligible women. After providing written informed consent to participate in the study, first, all participants were assessed for VVA through performing clinical examinations and checking the vaginal $\mathrm{PH}$ level. UI was evaluated using the International Consultation on

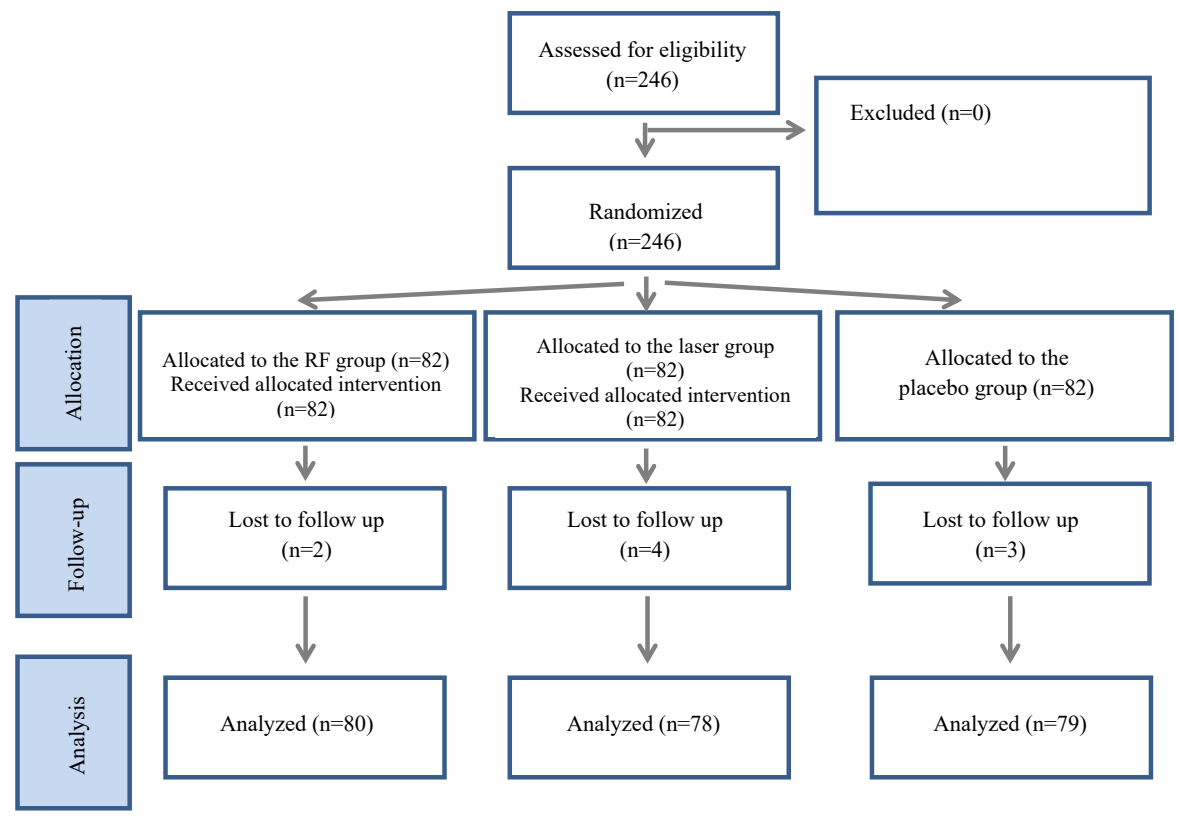

Figure 1. Flow Diagram of the Study. Note. RF: Radiofrequency. 
Incontinence (ICIQ-SF). In this study, only patients with MUI were studied and patients with other incontinence types were excluded from investigation. In addition, pelvic organ prolapse/urinary incontinence sexual questionnaire (PISQ-12), vaginal health index (VHI), and visual analog score (VAS) were used to determine sexual satisfaction. After a definitive diagnosis of UI and VVA and the randomized allocation of patients to each group, $\mathrm{RF}$ and laser treatments were performed in their own groups while patients in the control group only received the placebo treatment.

Laser treatment consisted of a series of three treatments using the fractional $\mathrm{CO}_{2}$ laser system 4 weeks apart taking about 1-2 minute(s) per session as an in-office procedure using the Monalisa Touch device aimed at treating VVA, MUI, and sexual problems. Treatment parameters included the power of $40 \mathrm{w}$, dwell time of $100 \mathrm{~ms}$, and $1000 \mathrm{~mm}$ spacing using a normal scan mode with the Smartstack setting of 1 and 3 for the first and the third treatment, respectively.

In the RF therapy group, all patients had 3 sessions of treatment with a frequency of 4-6 weeks. The Physio Vag Device, which is based on RF technology, was used in this study. The device works with both monopolar and bipolar modes, 4 working frequencies (i.e., 420, 500, 720, and 1000 $\mathrm{Hz}$ ), and both continuous and pulsed modes of operation. In this study, a frequency of $500 \mathrm{~Hz}$ was used for both intravaginal and extravaginal treatments. In general, the depth of the penetration of waves into the tissue is less at higher frequencies. Each treatment session was held in the group for 20 minutes (10 minutes for each of the intravaginal and extravaginal treatments) with a working temperature range of $38-44^{\circ} \mathrm{C}$. In the monopolar mode, $\mathrm{RF}$ waves are transmitted between the probe and the metal plate normally placed under the buttocks of the patient, creating a magnetic field between the probe and the plate. In this case, the waves have the highest penetration compared to the bipolar mode. In the bipolar mode, RF waves are transmitted between two electrodes designed on the bipolar probe. Hence, the amount of wave penetration will be less than that of the monopolar mode.

After the intervention, participants were examined in terms of UI and sexual satisfaction. Any possible pain and adverse outcome during the treatment were recorded as well.

\section{Instruments}

The Prolapse/Urinary Incontinence Sexual Questionnaire The PISQ-12 is a validated and reliable, self-administered questionnaire for evaluating sexual function in women with UI and/or pelvic organ prolapsed. It is composed of 12 items in behavioral-emotive (4 items), physical (5 items), and partner-related (3 items) domains. The first domain comprises questions about sexual desire, orgasm, excitement, and satisfaction. The physical domain contains questions about pain and UI during intercourse, avoidance of sexual function due to prolapse, and fear of urine or stool incontinence. The partner-related domain includes questions about erection disorder, early ejaculation, and orgasm. Responses are graded on a 5-point Likert-type scale from 'never' to 'always'. The score of each domain is calculated by adding the score of each question (15).

\section{International Consultation on Incontinence}

ICIQ-SF is a validated instrument that provides a brief measure to assess the impact of IU symptoms on the quality of life and the outcome of the UI treatment. It is composed of four items including the frequency of urinary incontinence, the amount of leakage, the overall impact of UI, and the self-diagnostic item. The score for the frequency of urine leakage ranges from 0 (never) to 5 (always). The amount of leakage scores is between 0 (none) and 6 (a large amount) in the form of paired numbers. The overall impact of the UI score ranges from zero to ten. The self-diagnostic portion of the questionnaire is not given a score. The total score for the ICIQ-SF is calculated as the sum of the obtained scores from the four items. Therefore, the overall range of the total score values is $0-21$, and higher scores indicate greater incontinence $(16,17)$.

\section{Vaginal Health Index}

The VHI has five items in the vaginal examination for assessment of vaginal health. These five items include vaginal elasticity, fluid volume, vaginal $\mathrm{pH}$ level, epithelial integrity, and moisture after treatment and at followups after the final treatment. Responses are graded on a 5-point Likert-type scale, and in total, the minimum and maximum scores for a VHI are 5 and 25, respectively (18).

\section{Visual Analog Score}

The severity of VVA symptoms such as irritation, itching, dryness, dispersion, and dysuria was evaluated by VAS before and after the intervention. The subject placed a mark representing the level of pain or discomfort (from asymptomatic to severe) on a four-point scale (19).

\section{Statistical Analysis}

The collected data were entered in SPSS, version 20. First, the $\underline{t}$ test and Mann-Whitney $U$ test were used to compare normally distributed and not normally distributed data, respectively. $P<0.05$ was considered statistically significant.

\section{Results}

In the present study, 9 out of 246 patients were excluded because of unwillingness to continue the study. Therefore, the data of 80 patients in the RF group, 78 patients in the laser group, and 79 patients in the placebo group underwent an assessment. The mean (standard deviation, SD) age of participants was $57.7 \pm 7.3,56.3 \pm 7.2$, and $54.8 \pm 11.5$ years in the RF, laser, and placebo groups, respectively. The mean $(\mathrm{SD})$ of gravity was $3.7( \pm 1.9)$, 
$3.9( \pm 2)$, and $3.9( \pm 2)$ and $3.3( \pm 1.6)$. Furthermore, the mean (SD) of the number of children was $3.2( \pm 1.6)$, 3.8 $( \pm 1.6)$, and $3.4( \pm 1.6)$ in the RF, laser, and placebo groups, respectively $(P=0.069)$. There was no difference between the three groups in terms of the mean (SD) of the type of delivery $(P>0.05)$. Before data analysis, the analysis of variance (ANOVA) assumptions such as normalization, homogeneity of variances, and homogeneity of slope regression were investigated and all three assumptions received confirmation. First, the Kolmogorov-Smirnov test was used and the results were obtained as $\mathrm{z}=1.28(P$ $=0.07)$ in VVA symptoms, $\mathrm{z}=1.53(P=0.06)$ in VHI, $\mathrm{z}=$ $1.1(P=0.8)$ in MUI, $\mathrm{z}=1.29(P=0.07)$ in the emotional behavior of sexual satisfaction questionnaire from PISQ-
12., $\mathrm{z}=0.48(P=0.62)$ in physical behavior, and $\mathrm{z}=2.04(P$ $=0.16$ ) in the partner-related domain (Table 1).

In terms of VVA symptoms, the results of ANOVA (Table 2) showed that there was a significant difference in the mean scores between the groups after the intervention $(\mathrm{F}=43.669, P<0.001)$. The results of Tukey test (Table 3) demonstrated that VVA symptoms in RF and laser groups decreased after the intervention although changes in the RF group were more compared to the laser group (15.813 vs. $10.075, P<0.001)$.

Regarding VHI, the results of ANOVA (Table 4) represented a significant difference in the mean scores of VHI between the groups after the intervention $(\mathrm{F}=173.23, P<0.001)$. Based on the results of Tukey test

Table 1. Comparison of Study Variables Before and After the Intervention

\begin{tabular}{|c|c|c|c|c|}
\hline & & Before the Intervention & After the Intervention & DYl \\
\hline & & Mean \pm SD & Mean \pm SD & $P$ value \\
\hline \multirow{3}{*}{ VAS } & RF group & $26.5 \pm 12.6$ & $13.5 \pm 9.9$ & $<0.001$ \\
\hline & Laser group & $23.3 \pm 12.6$ & $17.6 \pm 12.2$ & $<0.001$ \\
\hline & Placebo group & $24.5 \pm 15.8$ & $23.3 \pm 15.3$ & 0.006 \\
\hline \multirow{3}{*}{ VHI } & RF group & $10.1 \pm 2.1$ & $20.9 \pm 1.5$ & $<0.001$ \\
\hline & Laser group & $10.9 \pm 3.4$ & $12.7 \pm 4.8$ & 0.002 \\
\hline & Placebo group & $10.6 \pm 4.6$ & $10.5 \pm 4.0$ & 0.636 \\
\hline \multirow{3}{*}{ MUI } & RF group & $7.6 \pm 5.1$ & $4.1 \pm 3.6$ & $<0.001$ \\
\hline & Laser group & $6.5 \pm 3.3$ & $4.9 \pm 3.1$ & $<0.001$ \\
\hline & Placebo group & $6.7 \pm 4.0$ & $6.1 \pm 3.9$ & 0.067 \\
\hline \multirow{3}{*}{ Emotional behavior } & RF group & $6.7 \pm 3.3$ & $10.0 \pm 2.6$ & $<0.001$ \\
\hline & Laser group & $6.3 \pm 3.2$ & $7.9 \pm 3.2$ & $<0.001$ \\
\hline & Placebo group & $8.8 \pm 3.8$ & $8.8 \pm 3.8$ & 0.1 \\
\hline \multirow{3}{*}{ Physical behavior } & RF group & $11.4 \pm 4.0$ & $16.3 \pm 2.9$ & $<0.001$ \\
\hline & Laser group & $11.1 \pm 4.1$ & $10.5 \pm 4.2$ & 0.029 \\
\hline & Placebo group & $14 \pm 2.5$ & $14.5 \pm 2.7$ & 0.197 \\
\hline \multirow{3}{*}{ Partner related } & RF group & $6.7 \pm 2.2$ & $8.1 \pm 2.7$ & 0.002 \\
\hline & Laser group & $6.8 \pm 2.2$ & $6.9 \pm 2.1$ & 0.566 \\
\hline & Placebo group & $7.0 \pm 2.1$ & $7.3 \pm 2.9$ & 0.159 \\
\hline
\end{tabular}

Note. SD: Standard deviation; VAS: Visual analog score; VHI: Vaginal health index; MUI: Mixed urinary incontinence; RF: Radiofrequency.

Table 2. Results of ANOVA for VVA Symptoms

\begin{tabular}{|c|c|c|c|c|c|c|}
\hline & & Sum of Squares & $d f$ & Mean Square & $\mathbf{F}$ & $P$ Value \\
\hline \multirow{3}{*}{ Before the intervention } & Between groups & 411.233 & 2 & 205.617 & 1.080 & 0.341 \\
\hline & Within groups & 45109.763 & 234 & 12.374 & & \\
\hline & Sum & 45520.996 & 236 & & & \\
\hline \multirow{3}{*}{ After the intervention } & Between groups & 10252.258 & 2 & 5126.129 & 43.669 & $<0.001$ \\
\hline & Within groups & 27820.538 & 234 & 117.386 & & \\
\hline & Sum & 38072.796 & 236 & & & \\
\hline
\end{tabular}

Note. ANOVA: Analysis of variance; VVA: Vulvovaginal atrophy.

Table 3. Results of Tukey's Test for VVA Symptoms

\begin{tabular}{llccc}
\hline & & Mean Difference & Standard Error & \multicolumn{1}{c}{$\boldsymbol{P}$ Value } \\
\hline RF group & Laser group & -5.738 & 1.713 & 0.003 \\
& Placebo group & -15.813 & 1.713 & 1.73 \\
Laser group & Placebo group & -10.075 & $<0.001$ & $<.001$ \\
\hline
\end{tabular}

Note. RF: Radiofrequency; VVA: Vulvovaginal atrophy. 
Table 4. Results of ANOVA for VHI

\begin{tabular}{|c|c|c|c|c|c|c|}
\hline & & Sum of Squares & df & Mean Square & $\mathbf{F}$ & $P$-value \\
\hline \multirow{3}{*}{$\begin{array}{l}\text { Before the } \\
\text { intervention }\end{array}$} & Between groups & 31.158 & 2 & 15.579 & 1.259 & 0.286 \\
\hline & Within groups & 2932.575 & 234 & 12.374 & & \\
\hline & Sum & 2963.733 & 236 & & & \\
\hline \multirow{3}{*}{$\begin{array}{l}\text { After the } \\
\text { intervention }\end{array}$} & Between groups & 4813.427 & 2 & 2406.714 & 173.230 & $<0.001$ \\
\hline & Within groups & 3264.896 & 234 & 13.893 & & \\
\hline & Sum & 8078.324 & 236 & & & \\
\hline
\end{tabular}

Note. ANOVA: Analysis of variance; VHI: Vaginal health index.

Table 5. Results of Tukey's Test for VHI

\begin{tabular}{llccc}
\hline & & Mean Difference & Standard Error & \multicolumn{1}{c}{$\boldsymbol{P}$ Value } \\
\hline RF group & Laser group & 8.194 & 0.593 & $<.001$ \\
& Placebo group & 10.425 & 0.589 & 0.001 \\
Laser group & Placebo group & 2.231 & 0.589 & $<0.001$ \\
\hline
\end{tabular}

Note. SD: Standard deviation; VHI: Vaginal health index; RF: Radiofrequency.

(Table 5), VHI improved in RF and laser groups after the intervention although changes in the RF group were more considerable in comparison with the laser group (10.425 vs. $2.231, P<0.001)$.

As regards MUI symptoms, ANOVA results (Table 6) revealed a significant difference in the mean scores between the groups after the intervention $(\mathrm{F}=5.942$, $P=0.003$ ). The results of Tukey test (Table 7 ) showed that MUI symptoms in RF and laser group decreased after the intervention although changes in the laser group were not significant $(P<0.149)$.

Further, the results of ANOVA (Table 8) revealed that there was a significant difference in the mean scores of emotional behaviors between the groups after the intervention ( $\mathrm{F}=3.057, P=0.04)$. According to the results of Tukey's test, emotional behaviors improved in the RF group after the intervention $(P=0.04)$ although changes in the laser group were not significant. In addition, a significant difference was found between the groups regarding the mean scores of physical behavior after the intervention $(\mathrm{F}=56.49, P<0.001)$. Based on the results of Tukey's test (Table 9), physical behavior improved in $\mathrm{RF}$ and laser groups after the intervention. On the other hand, there were no significant differences between the groups with respect to the partner-related domain after the intervention $(\mathrm{F}=2.706, P=0.07)$.

\section{Discussion}

To the best of our knowledge, no previous study has so far compared the effectiveness of RF and laser methods for the treatment of females suffering from MUI and VVA symptoms. All previous studies have reported that the RF or laser treatment was effective in improving MUI and VVA symptoms in the intervention group compared to the control group.

The results of this study are comparable and validated with previous data. Most studies, similar to this study, demonstrated a significant reduction in incontinence symptoms while significant improvements in the quality of life and sexual function in women who used the RF

Table 6. Results of ANOVA for MUI

\begin{tabular}{|c|c|c|c|c|c|c|}
\hline & & Sum of Squares & df & Mean Square & $\mathbf{F}$ & $P$-value \\
\hline \multirow{3}{*}{$\begin{array}{l}\text { Before the } \\
\text { intervention }\end{array}$} & Between groups & 53.930 & 2 & 26.965 & 1.508 & 0.224 \\
\hline & Within groups & 3969.199 & 222 & 17.879 & & \\
\hline & Sum & 4023.129 & 224 & & & \\
\hline \multirow{3}{*}{$\begin{array}{l}\text { After the } \\
\text { intervention }\end{array}$} & Between groups & 155.992 & 2 & 77.996 & 5.942 & 0.003 \\
\hline & Within groups & 2743.570 & 209 & 13.127 & & \\
\hline & Sum & 2899.561 & 211 & & & \\
\hline
\end{tabular}

Note. ANOVA: Analysis of variance; MUI: Mixed urinary incontinence.

Table 7. Results of Tukey's Test for MUI

\begin{tabular}{|c|c|c|c|c|}
\hline & & Mean Difference & Standard Error & $P$ Value \\
\hline \multirow[t]{2}{*}{ RF group } & Laser group & -0.871 & 0.633 & 0.355 \\
\hline & Placebo group & -2.025 & 0.591 & 0.002 \\
\hline Laser group & Placebo group & -1.154 & 0.616 & 0.149 \\
\hline
\end{tabular}

Note. SD: Standard deviation; MUI: Mixed urinary incontinence; RF: Radiofrequency. 
Table 8. Results of ANOVA for Sexual Satisfaction

\begin{tabular}{|c|c|c|c|c|c|c|c|}
\hline & & & Sum of Squares & df & Mean Square & $\mathbf{F}$ & $P$ Value \\
\hline \multirow{6}{*}{$\begin{array}{l}\text { Emotional } \\
\text { behavior }\end{array}$} & \multirow{3}{*}{ Before the intervention } & Between groups & 220.710 & 2 & 110.355 & 9.405 & $<0.286$ \\
\hline & & Within groups & 1912.621 & 163 & 11.734 & & \\
\hline & & Sum & 2133.331 & 165 & & & \\
\hline & \multirow{3}{*}{ After the intervention } & Between groups & 68.523 & 2 & 34.261 & 3.057 & 0.04 \\
\hline & & Within groups & 1703.348 & 152 & 11.206 & & \\
\hline & & Sum & 1771.871 & 154 & & & \\
\hline \multirow{6}{*}{$\begin{array}{l}\text { Physical } \\
\text { behavior }\end{array}$} & \multirow{3}{*}{ Before the intervention } & Between groups & 910.243 & 2 & 455.122 & 36.412 & 0.123 \\
\hline & & Within groups & 2037.371 & 163 & 12.499 & & \\
\hline & & Sum & 2947.614 & 165 & & & \\
\hline & \multirow{3}{*}{ After the intervention } & Between groups & 1229.601 & 2 & 614.801 & 56.049 & $<0.001$ \\
\hline & & Within groups & 1667.275 & 152 & 10.969 & & \\
\hline & & Sum & 2896.877 & 154 & & & \\
\hline \multirow{6}{*}{$\begin{array}{l}\text { Partner related } \\
\text { domain }\end{array}$} & \multirow{3}{*}{ Before the intervention } & Between groups & 2.689 & 2 & 1.345 & 0.279 & 0.757 \\
\hline & & Within groups & 793.882 & 165 & 4.811 & & \\
\hline & & Sum & 796.571 & 167 & & & \\
\hline & \multirow{3}{*}{ After the intervention } & Between groups & 36.524 & 2 & 18.262 & 2.706 & 0.07 \\
\hline & & Within groups & 1039.183 & 154 & 6.748 & & \\
\hline & & Sum & 1075.707 & 156 & & & \\
\hline
\end{tabular}

Note. ANOVA: Analysis of variance.

Table 9. Results of Tukey's Test for Sexual Satisfaction

\begin{tabular}{|c|c|c|c|c|c|}
\hline & & & Mean Difference & SD & $P$ Value \\
\hline \multirow{3}{*}{ Emotional behavior } & RF group & Laser group & 1.767 & 0.718 & 0.39 \\
\hline & & Placebo group & 0.944 & 0.697 & 0.039 \\
\hline & Laser group & Placebo group & -0.823 & 0.616 & 0.377 \\
\hline \multirow{3}{*}{ Physical behavior } & RF group & Laser group & 5.760 & 710 & $<0.001$ \\
\hline & & Placebo group & -0.194 & 690 & 0.04 \\
\hline & Laser group & Placebo group & -5.955 & 609 & $<0.001$ \\
\hline
\end{tabular}

Note. SD: Standard deviation; RF: Radiofrequency.

method for the treatment of GSM symptoms such as UI and VVA (13,20-25). On the other hand, most other studies reported the laser method as a safe and effective treatment for improvements in sexual satisfaction indices and the quality of life and sexual function in women with UI and VVA symptoms (6,26-30).

The results of this clinical trial indicated that improvements in VVA and MUI symptoms were achievable by either the RF or laser treatment method. However, improvement rates were significantly higher with the RF treatment as compared with laser therapy. In addition, women with MUI in the behavioral-emotive domain had better sexual functions after the RF treatment compared to laser therapy, meaning that RF and laser treatment were effective for improving VVA and MUI symptoms while better results for VVA and MUI improvements were obtained in the RF group. Therefore, RF technology seems to be a more effective option in treating female MUI symptoms in menopausal women.

The review of the literature recommends that $\mathrm{RF}$ is a minimally invasive procedure for the treatment of female UI and improvements in the quality of life and sexual function. In other words, RF application seems to be a promising, reasonable alternative for the treatment of symptoms related to GSM $(13,31)$.

However, the sense of the improvement of symptoms and satisfaction may vary from woman to woman. In this study, two different treatment options were compared in different women with various levels of pain or discomfort, making the assessment difficult. On the other hand, the effectiveness of treatment protocols greatly depends on the applied device, and the variety of devices makes it difficult to compare the effectiveness of RF and laser devices (32).

The present study, as the first one to report on RF and laser for the treatment of VVA and MUI, gives a solid basis for future research. It is notable that the limitation of the present study was probably related to the short follow-up. However, in some studies, improvements were registered immediately at the end of treatment. Nevertheless, it has been reported that long-term treatment improves MUI and VVA symptoms.

\section{Conclusions}

In general, the results of this study showed a greater reduction in MUI and VVA symptoms in the RF group compared to the laser group. In addition, using the 
RF method for the treatment of GSM symptoms had significantly greater effects on the improvement of the quality of life and sexual satisfaction of menopausal women compared to laser therapy. Therefore, RF can be recommended as a safe and acceptable non-surgical method for the treatment of MUI and VVA symptoms.

\section{Authors' Contribution}

TE and ZG conceived and planned the implementation. Further, LG and FD carried out the implementation. Moreover, TE and LG contributed to sample preparation. JR performed the calculations of the research. Finally, all authors provided critical feedback and helped shape the research, analysis, and manuscript.

\section{Conflict of Interests}

Authors declare that they have no conflict of interests.

\section{Ethical Issues}

The study protocol conformed to the ethical guidelines of the 1975 Declaration of Helsinki. In this study, we considered written consent of the pregnant women, the confidentiality of personal data, and free measurements as the principles of medical ethics. The Ethics Committee of Tehran University of Medical Sciences approved this study under the ethics code IR.TUMS.IKHC.REC.1398.035. Additionally, the study was registered at Iranian Registry of Clinical Trials (identifier: IRCT20190708044143N1; https://www.irct.ir/trial/40663).

\section{Financial Support}

Reproductive Health Research Center, Tehran University of Medical Science, Tehran, Iran supported the study.

\section{Acknowledgments}

The authors of the manuscript would like to thank the staff of Valiasr Hospital and all women who volunteered to participate in the study.

\section{References}

1. Wańczyk-Baszak J, Woźniak S, Milejski B, Paszkowski T. Genitourinary syndrome of menopause treatment using lasers and temperature-controlled radiofrequency. Prz Menopauzalny. 2018;17(4):180-184. doi:10.5114/pm.2018.81743

2. Moral E, Delgado JL, Carmona F, et al. Genitourinary syndrome of menopause. Prevalence and quality of life in Spanish postmenopausal women. The GENISSE study. Climacteric. 2018;21(2):167-173. doi:10.1080/13697137.2017.1421921

3. Dillon B, Dmochowski R. Radiofrequency for the treatment of stress urinary incontinence in women. Curr Urol Rep. 2009;10(5):369374. doi:10.1007/s11934-009-0058-z

4. Schreiber Pedersen L, Lose G, Høybye MT, Elsner S, Waldmann A, Rudnicki M. Prevalence of urinary incontinence among women and analysis of potential risk factors in Germany and Denmark. Acta Obstet Gynecol Scand. 2017;96(8):939-948. doi:10.1111/ aogs.13149

5. Hutchinson-Colas J, Segal S. Genitourinary syndrome of menopause and the use of laser therapy. Maturitas. 2015;82(4):342345. doi:10.1016/j.maturitas.2015.08.001

6. Elser DM, Mitchell GK, Miklos JR, et al. Nonsurgical transurethral collagen denaturation for stress urinary incontinence in women: 12-month results from a prospective long-term study. J Minim Invasive Gynecol. 2009;16(1):56-62. doi:10.1016/j. jmig.2008.09.621

7. Elser DM, Mitchell GK, Miklos JR, et al. Nonsurgical transurethral radiofrequency collagen denaturation: results at three years after treatment. Adv Urol. 2011;2011:872057. doi:10.1155/2011/872057

8. Fritel X, Fauconnier A, Bader G, et al. Diagnosis and management of adult female stress urinary incontinence: guidelines for clinical practice from the French College of Gynaecologists and Obstetricians. Eur J Obstet Gynecol Reprod Biol. 2010;151(1):14-
19. doi:10.1016/j.ejogrb.2010.02.041

9. Walter JE, Larochelle A. No. 358-intravaginal laser for genitourinary syndrome of menopause and stress urinary incontinence. J Obstet Gynaecol Can. 2018;40(4):503-511. doi:10.1016/j. jogc.2017.11.040

10. Tien YW, Hsiao SM, Lee CN, Lin HH. Effects of laser procedure for female urodynamic stress incontinence on pad weight, urodynamics, and sexual function. Int Urogynecol J. 2017;28(3):469-476. doi:10.1007/s00192-016-3129-y

11. Shamout $S$, Campeau L. Stress urinary incontinence in women: current and emerging therapeutic options. Can Urol Assoc J. 2017;11(6 Suppl 2):S155-S158. doi:10.5489/cuaj.4613

12. Kang D, Han J, Neuberger MM, et al. Transurethral radiofrequency collagen denaturation for the treatment of women with urinary incontinence. Cochrane Database Syst Rev. 2015(3):CD010217. doi:10.1002/14651858.CD010217.pub2

13. Hersh L, Salzman B. Clinical management of urinary incontinence in women. Am Fam Physician. 2013;87(9):634-640.

14. Karcher C, Sadick N. Vaginal rejuvenation using energy-based devices. Int J Womens Dermatol. 2016;2(3):85-88. doi:10.1016/j. ijwd.2016.05.003

15. Momenimovahe Z, Pakgohar M, Montazeri A. Pelvic Organ Prolapse/Urinary Incontinence Sexual Questionnaire (PISQ-12): psychometric validation of the Iranian version. Int Urogynecol J. 2015;26(3):433-439. doi:10.1007/s00192-014-2520-9

16. Karmakar D, Mostafa A, Abdel-Fattah M. A new validated score for detecting patient-reported success on postoperative ICIQSF: a novel two-stage analysis from two large RCT cohorts. Int Urogynecol J. 2017;28(1):95-100. doi:10.1007/s00192-0163070-0

17. Klovning A, Avery K, Sandvik H, Hunskaar S. Comparison of two questionnaires for assessing the severity of urinary incontinence: the ICIQ-UI SF versus the incontinence severity index. Neurourol Urodyn. 2009;28(5):411-415. doi:10.1002/nau.20674

18. Arroyo C. Fractional $\mathrm{CO}(2)$ laser treatment for vulvovaginal atrophy symptoms and vaginal rejuvenation in perimenopausal women. Int J Womens Health. 2017;9:591-595. doi:10.2147/ijwh.s136857

19. Jokar A, Davari T, Asadi N, Ahmadi F, Foruhari S. Comparison of the hyaluronic acid vaginal cream and conjugated estrogen used in treatment of vaginal atrophy of menopause women: a randomized controlled clinical trial. Int J Community Based Nurs Midwifery. 2016;4(1):69-78.

20. Appell RA, Juma S, Wells WG, et al. Transurethral radiofrequency energy collagen micro-remodeling for the treatment of female stress urinary incontinence. Neurourol Urodyn. 2006;25(4):331336. doi:10.1002/nau.20185

21. Jo HM, Kim HS, Cho YW, Ahn SH. Two-year outcome of percutaneous bipolar radiofrequency neurotomy of sacral nerves s2 and s3 in spinal cord injured patients with neurogenic detrusor overactivity: a randomized controlled feasibility study. Pain Physician. 2016;19(6):373-380.

22. Lalji S, Lozanova P. Evaluation of the safety and efficacy of a monopolar nonablative radiofrequency device for the improvement of vulvo-vaginal laxity and urinary incontinence. J Cosmet Dermatol. 2017;16(2):230-234. doi:10.1111/jocd.12348

23. Leibaschoff G, Izasa PG, Cardona JL, Miklos JR, Moore RD. Transcutaneous temperature controlled radiofrequency (TTCRF) for the treatment of menopausal vaginal/genitourinary symptoms. Surg Technol Int. 2016;29:149-159.

24. Lordelo P, Vilas Boas A, Sodré D, Lemos A, Tozetto S, Brasil C. New concept for treating female stress urinary incontinence with radiofrequency. Int Braz J Urol. 2017;43(5):896-902. doi:10.1590/ s1677-5538.ibju.2016.0621

25. Vanaman Wilson MJ, Bolton J, Jones IT, Wu DC, Calame A, Goldman MP. Histologic and clinical changes in vulvovaginal tissue after treatment with a transcutaneous temperature-controlled radiofrequency device. Dermatol Surg. 2018;44(5):705-713. doi:10.1097/dss.0000000000001453

26. Blaganje M, Šćepanović D, Žgur L, Verdenik I, Pajk F, Lukanović 
A. Non-ablative Er:YAG laser therapy effect on stress urinary incontinence related to quality of life and sexual function: a randomized controlled trial. Eur J Obstet Gynecol Reprod Biol. 2018;224:153-158. doi:10.1016/j.ejogrb.2018.03.038

27. Gaspar A, Brandi H. Non-ablative erbium YAG laser for the treatment of type III stress urinary incontinence (intrinsic sphincter deficiency). Lasers Med Sci. 2017;32(3):685-691. doi:10.1007/ s10103-017-2170-5

28. González Isaza P, Jaguszewska K, Cardona JL, Lukaszuk M. Longterm effect of thermoablative fractional $\mathrm{CO}(2)$ laser treatment as a novel approach to urinary incontinence management in women with genitourinary syndrome of menopause. Int Urogynecol J. 2018;29(2):211-215. doi:10.1007/s00192-017-3352-1

29. Lin KL, Chou SH, Long CY. Effect of Er: YAG Laser for Women with Stress Urinary Incontinence. Biomed Res Int. 2019;2019:7915813. doi:10.1155/2019/7915813

30. Lin $\mathrm{YH}$, Hsieh WC, Huang L, Liang CC. Effect of non-ablative laser treatment on overactive bladder symptoms, urinary incontinence and sexual function in women with urodynamic stress incontinence. Taiwan J Obstet Gynecol. 2017;56(6):815820. doi:10.1016/j.tjog.2017.10.020

31. Lukban JC. Transurethral radiofrequency collagen denaturation for treatment of female stress urinary incontinence: a review of the literature and clinical recommendations. Obstet Gynecol Int. 2012;2012:384234. doi:10.1155/2012/384234

32. Qureshi AA, Tenenbaum MM, Myckatyn TM. Nonsurgical vulvovaginal rejuvenation with radiofrequency and laser devices: a literature review and comprehensive update for aesthetic surgeons. Aesthet Surg J. 2018;38(3):302-311. doi:10.1093/asj/ sjx138

(C) 2021 The Author(s); This is an open-access article distributed under the terms of the Creative Commons Attribution License (http:// creativecommons.org/licenses/by/4.0), which permits unrestricted use, distribution, and reproduction in any medium, provided the original work is properly cited. 